\title{
A randomised comparative study of the short term clinical and biological effects of intravenous pulse methylprednisolone and infliximab in patients with active rheumatoid arthritis despite methotrexate treatment
}

\author{
P Durez, A Nzeusseu Toukap, B R Lauwerys, D H Manicourt, P Verschueren, R Westhovens, \\ J-P Devogelaer, F A Houssiau
}

See end of article for authors' affiliations

.....................

Correspondence to: Dr F A Houssiau,

Rheumatology

Department, Cliniques

Universitaires Saint-Luc,

Université catholique de

Louvain, Avenue

Hippocrate, 10, B-1 200

Bruxelles, Belgium;

houssiau@ruma.ucl.ac.be

Accepted 10 October 2003

\begin{abstract}
Objectives: To compare the short term clinical and biological effects of intravenous (IV) pulse methylprednisolone (MP) and infliximab (IFX) in patients with severe active rheumatoid arthritis (RA) despite methotrexate (MTX) treatment.

Methods: Patients with active RA despite MTX treatment were randomly allocated to receive a single IV infusion of MP (1 g) or three IV infusions of IFX $(3 \mathrm{mg} / \mathrm{kg})$ on weeks 0,2 , and 6. Patients were "blindly" evaluated for disease activity measures. Quality of life (QoL) was evaluated through the SF-36 health survey. Serum matrix metalloproteinase-3 (MMP-3) titres were measured at baseline, weeks 2 and 6.

Results: Compared with baseline, significant improvement was noted in all activity measures, including serum $C$ reactive protein (CRP) titres, in the IFX group only. At week 14, 6/9 (67\%) and 4/9 (44\%) IFX patients met the ACR20 and 50 response criteria, while this was the case in only $1 / 12(8 \%)$ and $0 / 12(0 \%)$ MP patients, respectively $(p<0.05)$. None of the QoL scales improved with MP treatment, whereas some did so in the IFX group. Serum MMP-3 titres significantly decreased (41\% drop) at week 6 in the IFX group, while no changes were seen in patients given MP.

Conclusion: This short term randomised comparative study demonstrates that TNF blockade is better than MP pulse therapy in a subset of patients with severe refractory RA, with improvement in not only clinical parameters of disease activity but also biological inflammatory indices, such as serum CRP and MMP-3 titres.
\end{abstract}

ntravenous (IV) methylprednisolone (MP) pulse therapy has been proposed as treatment for severe rheumatoid arthritis (RA), in particular to achieve symptomatic relief in patients with active disease despite the use of disease modifying antirheumatic drugs (DMARDs). ${ }^{1-4}$

This strategy has been recently re-examined owing to the availability of tumour necrosis factor (TNF) antagonists. In several controlled studies, infliximab (IFX), ${ }^{5}$ adalimumab, $^{7}$ and etanercept ${ }^{8}$ have indeed been shown to be effective in MTX resistant RA, not only suppressing inflammation but also slowing down radiological progression, thereby offering a new therapeutic option for patients with refractory disease. The clinical benefits of TNF blockade in MTX resistant patients with RA have, however, never been compared in a randomised study with those of IV MP pulse therapy-an interesting issue, particularly given the differential costs between the two treatments.

In this study we compared the short term clinical and biological effects of IV MP and IFX in patients with active RA despite MTX treatment.

\section{PATIENTS AND METHODS}

\section{Inclusion and exclusion criterio}

Patients were eligible for this study if they met the American Rheumatism Association classification criteria for RA, ${ }^{9}$ were aged between 18 and 80 years, had a disease duration of more than 1 year, and had active disease (defined as the presence of a swollen joint count (SJC) $\geqslant 6$ (by the 66 joints count), a tender joint count (TJC) $\geqslant 6$ (by the 68 joints count), and at least two of the following disease activity criteria: morning stiffness $\geqslant 45 \mathrm{~min}$, erythrocyte sedimentation rate $>28 \mathrm{~mm} /$ lst $\mathrm{h}$, or serum $\mathrm{C}$ reactive protein $(\mathrm{CRP})>20 \mathrm{mg} / \mathrm{l})$, despite treatment with MTX at a weekly dose of $15 \mathrm{mg}$ ( $10 \mathrm{mg}$ when tolerance was poor). Exclusion criteria included past/current history of tuberculosis, human immunodeficiency virus infection, hepatitis $\mathrm{C}$ virus infection, expected poor compliance, current treatment with oral glucocorticoids at a daily dose $>10 \mathrm{mg}$ prednisolone equivalent, previous treatment with IV MP pulse and/or TNF antagonists. The study was approved by the ethics committee of the two hospitals participating in the trial and patients' informed consent was obtained before screening.

\section{Treatment protocol}

Twenty seven patients fulfilling the inclusion criteria were randomly allocated to the MP $(n=15)$ or $\operatorname{IFX}(n=12)$ group and followed up for 14 weeks. Patients randomised to the MP group received a single IV infusion of $1 \mathrm{~g}$ methylprednisolone (sodium hemisuccinate) at week 0 , whereas patients included in the IFX arm were given three IV infusions of IFX, at a dose of $3 \mathrm{mg} / \mathrm{kg}$, at weeks 0,2 , and 6 (standard induction therapy). Patients randomised to the MP group did not receive a sham perfusion on weeks 2 and 6. Oral glucocorticoid and MTX doses remained unchanged throughout

Abbreviations: ACR, American College of Rheumatology; CRP, C reactive protein; DMARD, disease modifying antirheumatic drug; IFX, infliximab; IL, interleukin; IV, intravenous; MMP, matrix metalloproteinase; MP, methylprednisolone; MTX, methotrexate; RA, rheumatoid arthritis; SJC, swollen joint count; TJC, tender joint count; TNF, tumour necrosis factor 
the study. Intra-articular steroid treatment was not allowed, nor the introduction of a new non-steroidal anti-inflammatory drug or DMARD.

\section{Patient assessment}

The following items were measured at baseline and at weeks $2,4,6,10$, and 14: SJC (by the 66 joints count), TJC (by the 68 joints count), patient's and physician's global assessments of disease activity (by a visual analogue scale: 0-100 mm), patient's assessment of pain (by a visual analogue scale: 0-100 mm), morning stiffness, Health Assessment Questionnaire (0-3 score), Short Form-36 (SF-36) Health Survey (0-100 score), and serum CRP titres. Patients were all evaluated by the same observer, who was not aware of randomisation until week 14, when the study was completed. The American College of Rheumatology (ACR) response score was evaluated at week 14 .

\section{Laboratory tests}

Serum MMP-3 and interleukin (IL)6 titres were determined at baseline, weeks 2 and 6 by enzyme linked immunosorbent assay (ELISA) ${ }^{10}$ and by the IL6 responsive 7TD1 hybridoma cell line bioassay, ${ }^{11}$ respectively.

\section{Statistics}

Data were analysed using non-parametric tests for paired values ("intragroup" comparisons; Wilcoxon matched-pair signed rank test) or unpaired values ("between-group" comparisons; Mann-Whitney $U$ test). Values of $p$ for the ACR20 and 50 response rates were calculated by Fisher's exact test.

\section{RESULTS}

\section{Baseline data}

Twenty eight consecutive patients with RA with active disease despite MTX were randomly allocated to the MP or IFX group but one patient randomised to the IFX arm declined to take part in the study before receiving the drug. Table 1 shows that the clinical and biological data of the two groups did not differ significantly at baseline, and neither did the MTX weekly dose nor the oral prednisolone daily dose. By the time of randomisation, patients had received the following DMARDs: MTX (by definition, according to the inclusion criteria), sulfasalazine ( $85 \%$ of the patients), gold salts $(79 \%)$, hydroxychloroquine $(61 \%)$, cyclosporin A $(58 \%)$, D-penicillamine $(42 \%)$, azathioprine $(30 \%)$, and leflunomide (18\%), with no differences between the MP and IFX groups (data not shown).

\section{Distinct effects of MP and IFX on clinical and biological measures of disease activity} In this subset of patients with severe active RA despite MTX, one IV pulse of MP ( $1 \mathrm{~g})$ did not significantly improve the measures of disease activity (fig 1). By contrast, for patients given IFX, the SJC, TJC, morning stiffness, Health Assessment Questionnaire, patient's and physician's assessments of global disease activity, patient's assessment of pain, and serum CRP titres significantly improved. Figure 2 shows that $6 / 9(67 \%)$ and $4 / 9(44 \%)$ IFX patients met the ACR20 and ACR50 response criteria at week 14, whereas this was the case in only $1 / 12(8 \%)$ and $0 / 12(0 \%)$ in the MP group, respectively. No patient met the ACR70 response criteria.

\section{Quality of life evaluation}

Quality of life (QoL) was evaluated at baseline and at week 14 through the Short Form-36 (SF-36) Health Survey. Table 2 shows that no significant improvement was noted in any of the SF-36 scales in the MP group. In the IFX group, significant improvement was noted at week 14 compared
Table 1 Baseline characteristics by treatment group

\begin{tabular}{lll}
\hline Variable & $\begin{array}{l}\text { MP } \\
\text { (n= 15) }\end{array}$ & $\begin{array}{l}\text { IFX } \\
\text { (n= 12) }\end{array}$ \\
\hline Female/male (\%) & $73 / 27$ & $100 / 0$ \\
Age (years) & $56(35-79)$ & $48(34-60)$ \\
$\begin{array}{l}\text { Disease duration (years) } \\
\text { Rheumatoid factor positivity (\%) }\end{array}$ & $12(1-24)$ & $10(2-20)$ \\
$\begin{array}{l}\text { Previous DMARDs (n) } \\
\text { Swollen joint count (n) }\end{array}$ & $3(1-7)$ & 67 \\
Tender joint count (n) & $22(7-38)$ & $16(2-6)$ \\
$\begin{array}{l}\text { Serum CRP (g/l) } \\
\text { Patient's assessment of pain (VAS, }\end{array}$ & $24(7-38)$ & $20(6-44)$ \\
100 mm) & $19(3-63)$ & $13(3-43)$ \\
$\begin{array}{l}\text { Patient's assessment of fatigue (VAS, } \\
100 \text { mm) }\end{array}$ & $60(13-100)$ & $50(15-80)$ \\
$\begin{array}{l}\text { Patient's global assessment of disease } \\
\text { activity (VAS, 100 mm) }\end{array}$ & $63(19-100)$ & $56(14-97)$ \\
$\begin{array}{l}\text { Physician's global assessment of } \\
\text { disease activity (VAS, 100 mm) }\end{array}$ & $58(18-83)$ & $43(15-80)$ \\
$\begin{array}{l}\text { Health Activity Questionnaire (score) } \\
\text { Morning stiffness (min) }\end{array}$ & $1.5(0.75-2.13)$ & $1.3(0.75-2)$ \\
$\begin{array}{l}\text { Prednisolone dose (mg/day) } \\
\text { Methotrexate dose (mg/week) }\end{array}$ & $114(30-420)$ & $76(30-150)$ \\
\hline
\end{tabular}

Values are median (range), except when expressed as percentages. DMARDs, disease modifying antirheumatic drugs; VAS, visual analogue scale.

The differences between the two treatment groups were not statistically significant.

with baseline for the item "bodily pain". Borderline significant improvement was observed in three additional scales ("physical functioning", "vitality", and "social functioning"). At week 14, the between-groups differences between MP and IFX patients were significant for four scales ("physical functioning", "bodily pain", "general health", and "social functioning").

\section{Side effects}

No serious infections or immunoallergic reactions were noted either in the IFX or in the MP group. Other side effects were minimal (MP group: one short lived episode of anxiety in week 2, pruritus in week 4, and neck pain in week 6; IFX group: one episode of labial Herpes simplex infection in week 2 , sore throat in week 10, and myalgias in week 10).

\section{Distinct effects of IFX and MP on serum matrix metalloproteinase-3 (MMP-3) and IL6 titres}

Serum MMP-3 and IL6 titres were measured at baseline, weeks 2 and 6 in both groups of patients (fig 3). Interestingly, the mean MMP-3 titres significantly decreased (41\% drop) at week 6 in the IFX group, whereas no changes were seen in patients given MP. Serum IL6 titres did not vary significantly over time in either group. However, the mean values measured in IFX patients at week 6 were significantly lower than those measured in the MP group.

\section{Effects of IFX in patients initially randomised to the MP group}

When the protocol was completed, all patients randomised to the MP group were given IFX in an open design and their clinical and biological data were collected. Figure 4 shows that significant improvement in the SJC, TJC, and serum CRP titres was seen in these patients, as soon as 2 weeks after their first IFX perfusion, thereby indicating that these very patients were not refractory to treatment.

\section{DISCUSSION}

To the best of our knowledge, this is the first randomised study aimed at comparing the effects of MP pulse therapy and IFX in patients with active RA despite MTX. The results 

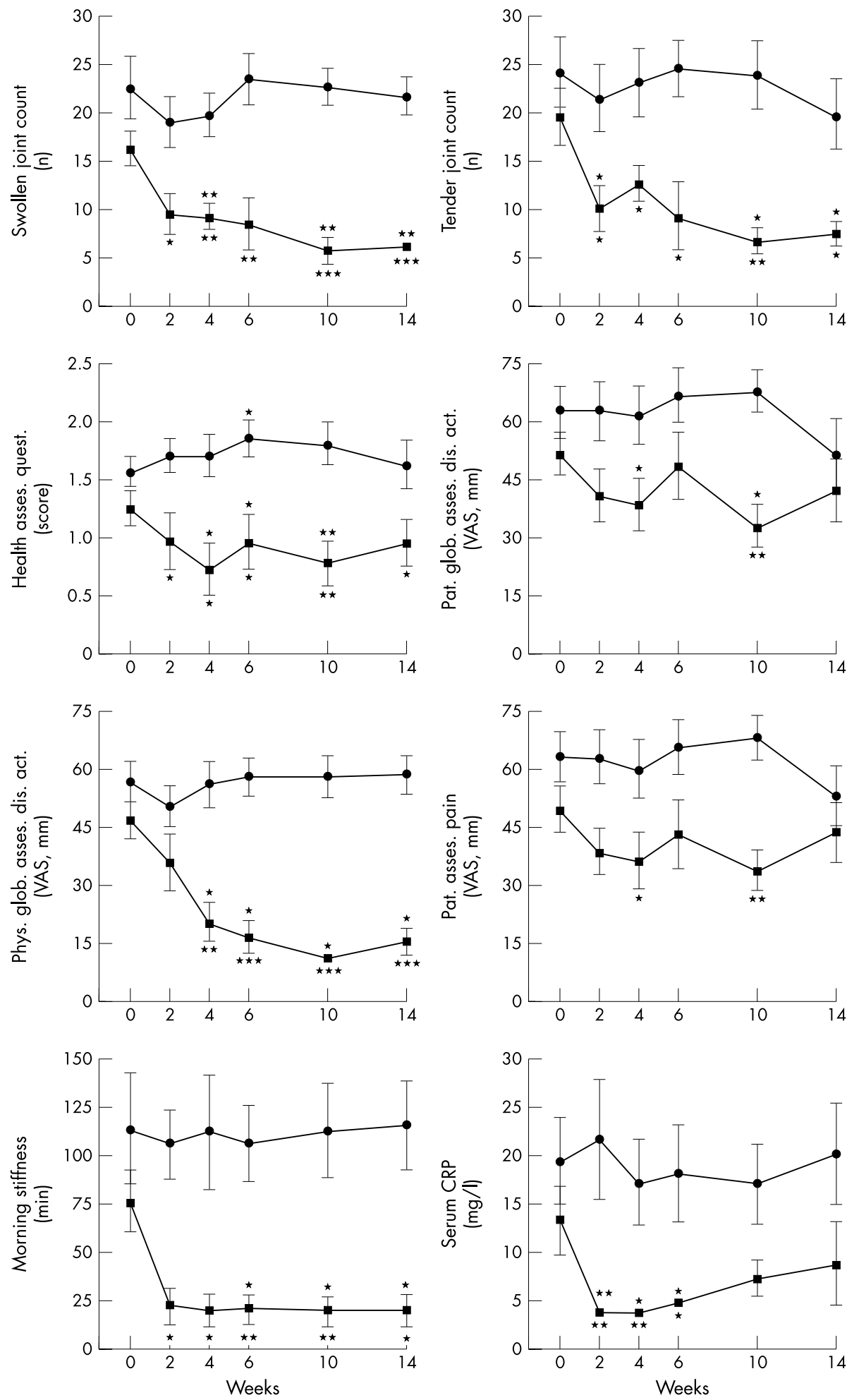

Figure 1 Disease activity measures in patients treated with MP pulse (circles) or IFX (squares). Results are presented as means (SEM). Asterisks placed below the squares refer to between-groups $p$ values. Asterisks placed above the squares or the circles refer to intragroup $p$ values. ${ }^{*} p<0.05$; ${ }^{* *} p<0.005 ;{ }^{* * *} p<0.0005$.

presented here show that TNF blockade is better than MP pulse treatment in a subset of patients with severe refractory RA, with improvement not only in clinical measures of disease activity but also in biological inflammatory indices, such as serum CRP titres. Of note, significant betweengroups differences were seen as soon as week 2-that is, after only one infusion of IFX.
Although the clinical effects of IFX are well in line with those published previously, ${ }^{56}$ the absence of significant effect of MP pulse therapy contrasts with some previously published studies. ${ }^{1-4} \mathrm{~A}$ bias in patient selection most probably accounts for this discrepancy rather than differences between pulse regimens (our patients received only a single MP pulse). As indicated by the baseline data summarised in 


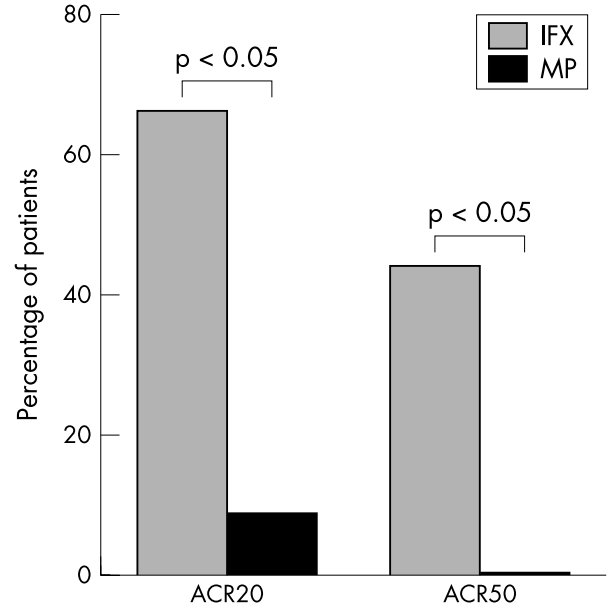

Figure 2 American College of Rheumatology (ACR) 20 and 50 response rates at week 14 in patients treated with IFX or MP. Owing to missing TJC values, the ACR response rates could be calculated for only 12 and 9 patients from the MP and IFX group, respectively.

table 1 , the disease in patients with RA recruited in this trial was among the most active and most refractory seen in our arthritis clinic. This bias in patient selection probably explains why our results differ from those reported by Nossent et al. ${ }^{12}$ In a non-randomised study performed in 19 patients with flaring RA, they found that IV MP and IFX had similar beneficial effects. It should be emphasised, however, that only half of these patients were treated with MTX, whereas all our patients were given that drug and still had active disease. Incidentally, our patients randomised to the IV MP group were offered open treatment with IFX when the protocol was completed and dramatically responded to TNF
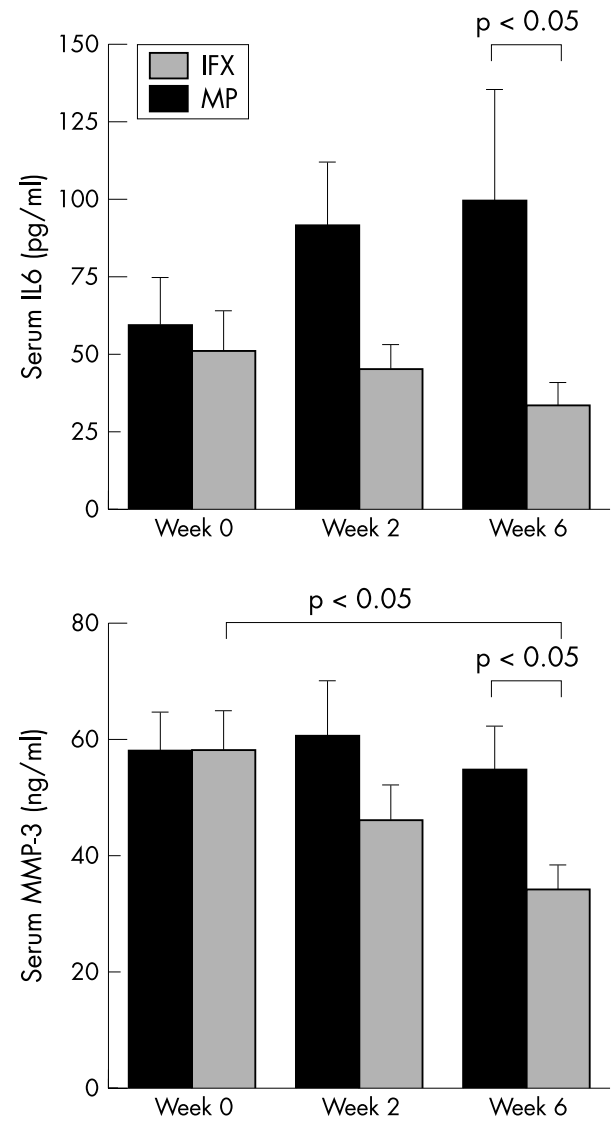

Figure 3 Serum IL6 and MMP-3 titres measured in patients treated with IFX or MP. Results are means (SEM). Significant between-groups and intragroup differences are indicated by corresponding $p$ values.

\begin{tabular}{|c|c|c|c|c|}
\hline $\begin{array}{l}\text { SF-36 scales } \\
(0-100 ; 0=\text { worst health) }\end{array}$ & & MP & IFX & $\mathrm{p}$ (MP v IFX \\
\hline Physical functioning & $\begin{array}{l}\text { Week } 0 \\
\text { Week } 14 \\
\text { p (w0 } v \text { wl } 4)\end{array}$ & $\begin{array}{l}27(26) \\
24(26) \\
0.29\end{array}$ & $\begin{array}{l}36(22) \\
55(23) \\
0.06\end{array}$ & $\begin{array}{l}0.10 \\
0.01\end{array}$ \\
\hline Role-physical & $\begin{array}{l}\text { Week } 0 \\
\text { Week } 14 \\
\text { p (w0 v w1 4) }\end{array}$ & $\begin{array}{l}13(28) \\
35(41) \\
0.16\end{array}$ & $\begin{array}{l}42(48) \\
45(42) \\
0.99\end{array}$ & $\begin{array}{l}0.18 \\
0.43\end{array}$ \\
\hline Bodily pain & $\begin{array}{l}\text { Week } 0 \\
\text { Week } 14 \\
\text { p (w0 } v \text { w1 4) }\end{array}$ & $\begin{array}{l}26(16) \\
32(24) \\
0.99\end{array}$ & $\begin{array}{l}35(23) \\
52(16) \\
0.04\end{array}$ & $\begin{array}{l}0.32 \\
0.05\end{array}$ \\
\hline General health & $\begin{array}{l}\text { Week } 0 \\
\text { Week } 14 \\
\text { p (w0 v w14) }\end{array}$ & $\begin{array}{l}26(19) \\
29(22) \\
0.77\end{array}$ & $\begin{array}{l}40(16) \\
50(16) \\
0.15\end{array}$ & $\begin{array}{l}0.04 \\
0.02\end{array}$ \\
\hline Vitality & $\begin{array}{l}\text { Week } 0 \\
\text { Week } 14 \\
\text { p (w0 v w14) }\end{array}$ & $\begin{array}{l}27(20) \\
29(22) \\
0.99\end{array}$ & $\begin{array}{l}31(25) \\
45(20) \\
0.08\end{array}$ & $\begin{array}{l}0.93 \\
0.07\end{array}$ \\
\hline Social functioning & $\begin{array}{l}\text { Week } 0 \\
\text { Week } 14 \\
\text { p (w0 v w14) }\end{array}$ & $\begin{array}{l}44(16) \\
40(25) \\
0.58\end{array}$ & $\begin{array}{l}53(30) \\
66(22) \\
0.06\end{array}$ & $\begin{array}{l}0.38 \\
0.03\end{array}$ \\
\hline Role-emotional & $\begin{array}{l}\text { Week } 0 \\
\text { Week } 14 \\
\text { p (w0 v w14) }\end{array}$ & $\begin{array}{l}22(39) \\
39(47) \\
0.31\end{array}$ & $\begin{array}{l}58(47) \\
67(42) \\
0.93\end{array}$ & $\begin{array}{l}0.06 \\
0.18\end{array}$ \\
\hline Mental health & $\begin{array}{l}\text { Week } 0 \\
\text { Week } 14 \\
\text { p (w0 v wl } 4)\end{array}$ & $\begin{array}{l}45(21) \\
45(22) \\
0.65\end{array}$ & $\begin{array}{l}52(25) \\
60(23) \\
0.31\end{array}$ & $\begin{array}{l}0.48 \\
0.22\end{array}$ \\
\hline
\end{tabular}




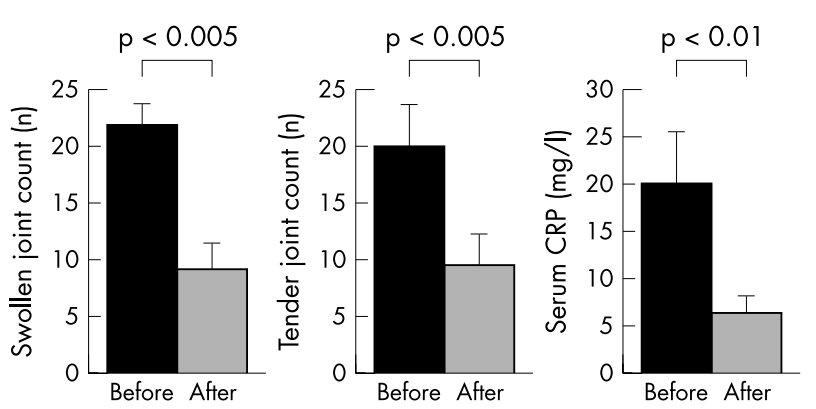

Figure 4 Disease activity measures in patients randomised to the MP group and given open access to IFX treatment, immediately before and 2 weeks after the first IFX injection. Results are means (SEM). Significant differences are indicated by corresponding $\mathrm{p}$ values.

blockade, thereby lending further support to view that TNF blockade is better than MP pulse therapy in this subset of patients with severe disease.

The observation that serum MMP-3 titres drop by $41 \%$ in the IFX group is well in keeping with previous data ${ }^{13}$ and sharply contrasts with the absence of effects of pulse MP treatment, an observation already made at the synovial membrane level. ${ }^{14}$ Actually, it was shown that oral glucocorticoid therapy increases serum MMP-3 titres. $^{15}{ }^{16}$ These distinct effects of MP and IFX on MMP-3 expression might be relevant to further damage, given the important role played by the enzyme in degrading many components of the cartilage and bone extracellular matrix and in activating proMMPs into their active form (such as MMP-1 and MMP-9). ${ }^{17}$

The trend towards down regulation of serum IL6 titres observed in the IFX group, although not statistically significant compared with baseline, contrasts with the complete absence of an inhibitory effect of IV MP on IL6 production. This observation might be relevant for the clinical effect of TNF blockade because IL6 is induced in active RA, ${ }^{11}$ and IL6 blockade was recently shown to display positive clinical and biological effects in patients with RA. ${ }^{18}$

Our study has some potential limitations, especially the choice of the IV MP regimen and the absence of sham infusion in the IV MP group. Among the many IV MP pulse regimens (ranging from one to five infusions of $250 \mathrm{mg}$ to $1 \mathrm{~g}$, according to the proposed standardised nomenclature for glucocorticoid dosages and treatment regimen ${ }^{19}$ ), we chose a single IV infusion of $1 \mathrm{~g}$ based on our clinical practice in RA over the past 20 years. Although it has been shown in two separate trials that an IV MP pulse of $1 \mathrm{~g}$ is not more beneficial for patients with RA than lower (250 and $320 \mathrm{mg}$ ) doses, ${ }^{20}{ }^{21}$ the efficacy of a single IV MP pulse of $1 \mathrm{~g}$ compared with repeated pulses of $1 \mathrm{~g}$ has not been compared to the best of our knowledge. The possibility that a more incisive MP regimen (three pulses of $1 \mathrm{~g}$ in 5 days) would have given better results can indeed be considered, but potential toxicity issues were also taken into account. The absence of sham infusions at weeks 2 and 6 in the IV MP group is another caveat. It should be emphasised, however, that by week 2 all patients had received an infusion. Yet, only those patients given IFX improved clinically and biologically, thereby suggesting that the differential effects of IFX and MP confirmed on later follow up visits were not merely due to a placebo effect linked to two additional infusions.

Unpublished data indicate that IFX is efficient in achieving rapid disease control and in suppressing radiological progression in early RA. ${ }^{22}$ Therefore, as suggested in a recent editorial, ${ }^{23}$ comparative studies between glucocorticoids and TNF antagonists should be performed not only in refractory $\mathrm{RA}$, as in this study, but also in early disease, the more so as glucocorticoids have been proposed as part of the remission inducing phase of treatment. ${ }^{24}$ Such studies should ideally include pharmacoeconomic issues.

\section{DISCLOSURE}

Patrick Durez and René Westhovens are consultants for Schering-Plough (Belgium).

\section{ACKNOWLEDGEMENTS}

Schering-Plough (Belgium) kindly supported this study initiated by the investigators by providing IFX (Remicade) vials and a grant.

\section{Authors' affiliations}

P Durez, A Nzeusseu Toukap, B R Lauwerys, D H Manicourt, J-P Devogelaer, F A Houssiau, Rheumatology Department, Cliniques Universitaires Saint-Luc, Université catholique de Louvain, Belgium

P Verschueren, R Westhovens, Rheumatology Department, UZ Gasthuisberg, Katholieke Universiteit Leuven, Belgium

PD and ANT equally contributed to this work

\section{REFERENCES}

1 Weusten BL, Jacobs JW, Bijlsma JW. Corticosteroid pulse therapy in active rheumatoid arthritis. Semin Arthritis Rheum 1993;23:183-92.

2 Smith MD, Bertouch JV, Smith AM, Weatherall M, Ahern MJ, Brooks PM, et al. The clinical and immunological effects of pulse methylprednisolone therapy in rheumatoid arthritis. I. Clinical effects. J Rheumatol 1988; 15:229-32.

3 van der Veen MJ, Bijlsma JW. The effect of methylprednisolone pulse therapy on methotrexate treatment of rheumatoid arthritis. Clin Rheumatol 1993;12:500-5.

4 Corkill MM, Gibson T, Panayi GS. Pulse treatment with methylprednisolone in rheumatoid arthritis. BMJ 1990;301:446.

5 Maini R, St Clair EW, Breedveld F, Furst D, Kalden J, Weisman M, et al. Infliximab (chimeric anti-tumour necrosis factor alpha monoclonal antibody) versus placebo in rheumatoid arthritis patients receiving concomitant methotrexate: a randomised phase III trial. ATTRACT Study Group. Lancet 1999;354:1932-9.

6 Lipsky PE, van der Heijde DM, St Clair EW, Furst DE, Breedveld FC, Kalden JR, et al. Infliximab and methotrexate in the treatment of rheumatoid arthritis. Anti-Tumor Necrosis Factor Trial in Rheumatoid Arthritis with Concomitant Therapy Study Group. N Engl J Med 2000;343:1594-602.

7 Weinblatt ME, Keystone EC, Furst DE, Moreland LW, Weisman MH, Birbara CA, et al. Adalimumab, a fully human anti-tumor necrosis factor alpha monoclonal antibody, for the treatment of rheumatoid arthritis in patients taking concomitant methotrexate: the ARMADA trial. Arthritis Rheum 2003;48:35-45.

8 Weinblatt ME, Kremer JM, Bankhurst AD, Bulpitt KJ, Fleischmann RM, Fox RI, et al. A trial of etanercept, a recombinant tumor necrosis factor receptor: $\mathrm{Fc}$ fusion protein, in patients with rheumatoid arthritis receiving methotrexate. N Engl J Med 1999;340:253-9.

9 Arnett FC, Edworthy SM, Bloch DA, McShane DJ, Fries JF, Cooper NS, et al. The American Rheumatism Association 1987 revised criteria for the classification of rheumatoid arthritis. Arthritis Rheum 1988;31:315-24.

10 Manicourt DH, Fujimoto N, Obata K, Thonar EJ. Levels of circulating collagenase, stromelysin-1, and tissue inhibitor of matrix metalloproteinases 1 in patients with rheumatoid arthritis. Relationship to serum levels of antigenic keratan sulfate and systemic parameters of inflammation. Arthritis Rheum 1995;28:1031-9.

11 Houssiau FA, Devogelaer JP, Van Damme J, Nagant de Deuxchaisnes C, Van Snick J. Interleukin-6 in synovial fluid and serum of patients with rheumatoid arthritis and other inflammatory arthritides. Arthritis Rheum 1988;31:784-8.

12 Nossent HC, Bakland G, Aslaksen HK, Olsen G, Nordvag BY. Efficacy of methylprednisolone pulse therapy versus infliximab in the treatment of severe flares of chronic polyarthritis. Scand J Rheumatol 2001;30:335-9.

13 Brennan FM, Browne KA, Green PA, Jaspar JM, Maini RN, Feldmann M Reduction of serum matrix metalloproteinase 1 and matrix metalloproteinase 3 in rheumatoid arthritis patients following anti-tumour necrosis factor-alpha (cA2) therapy. Br J Rheumatol 1997;36:643-50.

14 Wong P, Cuello C, Bertouch JV, Roberts-Thomson PJ, Ahern MJ, Smith MD, et al. The effects of pulse methylprednisolone on matrix metalloproteinase and tissue inhibitor of metalloproteinase-1 expression in rheumatoid arthritis. Rheumatology (Oxford) 2000;39:1067-73.

15 Ribbens C, Martin y Porras M, Franchimont N, Kaiser M-J, Jaspar J-M, Damas $P$, et al. Increased matrix metalloproteinase- 3 serum levels in rheumatic diseases: relationship with synovitis and steroid treatment. Ann Rheum Dis 2002;61:161-6.

16 Sharif M, Salisbury C, Taylor DJ, Kirwan JR. Changes in biochemical markers of joint tissue metabolism in a randomized controlled trial of glucocorticoid in early rheumatoid arthritis. Arthritis Rheum 1998;41:203-9.

17 Cawston T. Matrix metalloproteinases and TIMPs: properties and implications for the rheumatic diseases. Mol Med Today 1998;4:130-7. 
18 Choy EHS, Isenberg DA, Garrood T, Farrow S, loannou Y, Bird H, et al. Therapeutic benefit of blocking interleukin-6 activity with an anti-interleukin-6 receptor monoclonal antibody in rheumatoid arthritis. Arthritis Rheum 2002:46:3143-50.

19 Buttgereit F, da Silva JAP, Boers M, Burmester G-R, Cutolo M, Jacobs J, et al. Standardised nomenclature for glucocorticoid dosages and glucocorticoid treatment regimens: currrent questions and tentative answers in rheumatology. Ann Rheum Dis 2002;61:718-22.

20 Vischer TL, Sinniger M, OH H, Gerster JC. A randomized, double-blind trial comparing a pulse of 1000 with $250 \mathrm{mg}$ methylprednisolone in rheumatoid arthritis. Clin Rheumatol 1986;5:325-6.
21 Radia M, Furst DE. Comparison of three pulse methylprednisolone regimens in the treatment of rheumatoid arthritis. J Rheumatol 1988;15:242-6.

22 Smolen JS, Emery P, Bathon J, Keystone E, Maini RN, Kalden J, et al. Rheumatoid arthritis-treatment. Ann Rheum Dis 2003;62(suppl I):64.

23 Moreland LW, O'Dell JR. Glucocorticoids and rheumatoid arthritis. Back to the future? Arthritis Rheum 2002;46:2553-63.

24 Boers M, Verhoeven AC, Markusse HM, van de Laar MA, Westhovens R, van Denderen JC, et al. Randomised comparison of combined step-down prednisolone, methotrexate and sulphasalazine with sulphasalazine alone in early rheumatoid arthritis. Lancet 1997;350:309-18.

\section{Call for papers}

10th European Forum on Quality Improvement in Health Care 13-15 April 2005, ExCel, Docklands, London

For further information on how to submit your paper please go to:

http://www.quality.bmjpg.com 